\title{
Acute lymphoblastic leukaemia: four-year survivals old and new
}

\author{
RM HARDISTY, MORWENNA M TILL, AND JULIAN PETO* \\ From the Department of Haematology, Institute of Child Health and Hospital for Sick Children, \\ Great Ormond Street, London, and *the ICRF Cancer Epidemiology and Clinical Trials Unit, \\ University of Oxford, UK
}

SUMMARY Two groups of four-year survivors with acute lymphoblastic leukaemia (ALL) are compared: an 'old' series consisting of 83 patients diagnosed before 1968, and a 'new' series of 366 patients included in Medical Research Council trials (UKALL I-III) and diagnosed in 1970-4. Both series differed significantly from a group of ALL patients who survived less than four years in having lower total leucocyte and blast-cell counts at diagnosis, but the new series did not show the significant differences in organ involvement and platelet count seen in the old series.

In both series, girls were more likely than boys to survive for four years and less likely to have relapsed meanwhile; in the new series, relapse rates were also lower for girls than for boys after four years, and subsequent survival was significantly better.

There was no difference between the two series in survival rates of those patients who had relapsed before reaching four years. A much higher proportion of the new series, however, had reached four years without prior relapse, and these had a more favourable subsequent survival than the corresponding group of the old series. About $90 \%$ of patients achieving four years' continuous complete remission on these UKALL regimes seem likely to survive for 10 years.

In 1973 we analysed the subsequent fate of 100 patients collected from all over the British Isles ${ }^{1}$ who had survived more than four years after diagnosis of acute leukaemia. Most of these patients had received much less chemotherapy than would now be considered appropriate, and they were obviously a highly selected group, representing only a very small proportion of those diagnosed as having leukaemia during the period in question (1953-67). Among the 83 patients with acute lymphoblastic leukaemia (ALL), disease-free survival for four years appeared to carry about a $70 \%$ chance of very long survival, and perhaps cure, whereas the corresponding chance for those who had survived four years despite one or more previous relapses was only about $17 \%$.

Since the time of diagnosis of these patients, the outlook for patients with ALL, and particularly for children, has been greatly improved by the introduction of continued combination chemotherapy and 'prophylactic' treatment of the central nervous system. In Britain, important contributions to these advances have been made through the series of UKALL trials carried out for the Medical Research Council by its Working Party on Leukaemia in
Childhood, which have been coordinated by $\mathrm{Dr}$ Humphrey Kay. ${ }^{2-5}$ Remissions of four years and more are therefore now being achieved in a much higher proportion of such patients than formerly, and it seems appropriate to enquire whether the conclusions drawn from the earlier series can be extrapolated to those treated by modern methods. We have therefore conducted a similar analysis of patients entered on UKALL trials I, II, and III between August 1970 and December 1974 for comparison with our findings in the previous series.

\section{Patients}

OLD SERIES

The 83 patients with ALL in the original series ${ }^{1}$ had all been diagnosed during the years 1953-67. Although they were not derived from a previously defined population, calculations based on the Registrar General's mortality figures suggested that the children in the series represented about $1.5 \%$ of all those diagnosed during the same period. All surviving members of the series have continued to be followed up, and the present analysis is based on 
the most recent data available, collected during late 1979 and 1980.

\section{NEW SERIES}

Between the start of the Medical Research Council's UKALL series of trials in August 1970 and the end of 1974, 786 patients were entered on UKALL I, II, and III. Of these, 113 in UKALL I received no early CNS prophylaxis with either radiotherapy or intrathecal methotrexate (though many of them received such treatment later when its benefit became clear), and these have therefore been excluded from the present analysis, leaving a total of 673 patients entered on the three trials. All of these received induction therapy with vincristine and prednisolone (and most with asparaginase also), CNS prophylaxis and subsequent multiple-agent chemotherapy with methotrexate, mercaptopurine, vincristine, prednisolone, and sometimes other drugs. Treatment was stopped after six, eight, or twelve 12-week cycles of maintenance therapy in those who remained in complete remission. Detailed protocols of the three trials are given in a 1977 report of the Medical Research Council Working Party on Leukaemia in Childhood. ${ }^{6}$ Of the 673 patients, $366(54 \%)$ remained alive four years after diagnosis; the present analysis is based on the state of these patients on 31 December 1979, giving a total possible follow-up of five to nine years, including at least one year after the end of chemotherapy for those who had not relapsed.

STATISTICAL ANALYSIS

Actuarial survival curves and associated significance tests were computed as described by Peto et al. ${ }^{7}$

\section{Results}

AGE AND SEX

There was no significant difference in the age
Hardisty, Till, and Peto

distribution of the patients in the two series of $\frac{0}{\vec{*}}$ four-year survivors, but within the new series there was a significantly higher proportion $(\mathrm{P}<0.001)$ of $\overrightarrow{\vec{F}}$ patients aged 7 or over among those who died $\stackrel{5}{9}$ before four years (Table 1 ).

Table 1 Age distribution

\begin{tabular}{|c|c|c|c|c|c|}
\hline \multirow[t]{2}{*}{ Series } & \multicolumn{5}{|c|}{$\operatorname{Age}(y r)$} \\
\hline & $<7$ & $7-13$ & $14-19$ & $20+$ & \\
\hline Old series & & & & & \\
\hline $\begin{array}{l}\text { Four-year survivors } \\
\text { New series }\end{array}$ & 56 & 21 & 3 & 3 & ns \\
\hline Four-year survivors & 259 & 81 & 19 & 7 & \\
\hline Died before four $\mathrm{yr}$ & 175 & 78 & 29 & 25 & $\mathrm{P}<0.001$ \\
\hline
\end{tabular}

The sex distribution of both series of patients is $\dot{\omega}$ shown in Table 2 . In the new series, significantly more girls than boys survived for four years $(62 \%$ versus $49 \% ; P<0.01$ ), and the sex difference in the $\frac{}{工}$ proportion of four-year complete remissions was $\vec{r}$ still greater $(53 \%$ versus $31 \% ; \mathrm{P}<0.0001)$. Al- $\frac{3}{0}$ though such calculations cannot be performed in $\frac{\bar{S}}{\partial}$ the case of the old series, since the starting population is undefined, there is no reason to suppose that ${ }_{\infty}$ the sex incidence of ALL has altered during the last. 30 years. The similarity of the sex ratios in both series in respect of both four-year survivals and $\sum$ four-year complete remissions therefore suggests that the female sex carried a proportionately similar advantage for patients treated by old- $\stackrel{\mathbb{Q}}{\complement}$ fashioned and by modern methods. Of the boys, $\overrightarrow{\overrightarrow{\vec{O}}}$ $45 \%$ in the old series but only $27 \%$ in the new series were aged over 6 years at diagnosis $(P<0.05)$; the corresponding proportions of older girls were $21 \%$ 움 and $32 \%$ (not significant).

FEATURES AT DIAGNOSIS

The proportion of patients in each series with clinical enlargement of spleen, liver, or lymph nodes

Table 2 Sex distribution

\begin{tabular}{|c|c|c|c|c|c|c|c|c|}
\hline & \multicolumn{5}{|c|}{ New series $(1970-4)$} & \multicolumn{3}{|c|}{ Old series (1953-67) } \\
\hline & \multirow[t]{2}{*}{ Total entry } & \multirow{2}{*}{$\begin{array}{l}\text { Died before } \\
4 \mathrm{yr}^{*}\end{array}$} & \multicolumn{3}{|c|}{ At four years* } & \multicolumn{3}{|c|}{ At four years } \\
\hline & & & $\begin{array}{l}\text { Alive after } \\
\text { relapse }\end{array}$ & Never relapsed & Total & $\begin{array}{l}\text { Alive after } \\
\text { relapse }\end{array}$ & Never relapsed & Total \\
\hline Male & 394 & $\begin{array}{l}200 \\
(51)\end{array}$ & $\begin{array}{l}73 \\
(19)\end{array}$ & $\begin{array}{l}121 \\
(31)\end{array}$ & $\begin{array}{l}194 \\
(49)\end{array}$ & 25 & 15 & 40 \\
\hline Female & 279 & $\begin{array}{l}107 \\
(38)\end{array}$ & $\begin{array}{l}23 \\
(8)\end{array}$ & $\begin{array}{l}149 \\
(53)\end{array}$ & $\begin{array}{l}172 \\
(62)\end{array}$ & 21 & 22 & 43 \\
\hline Total & 673 & $\begin{array}{l}307 \\
(46)\end{array}$ & $\begin{array}{l}96 \\
(14)\end{array}$ & $\begin{array}{l}270 \\
(40)\end{array}$ & $\begin{array}{l}366 \\
(54)\end{array}$ & 46 & 37 & 83 \\
\hline $\mathbf{M}: \mathbf{F}$ & $1 \cdot 4: 1$ & $1 \cdot 9: 1$ & $3 \cdot 2: 1$ & $0 \cdot 8: 1$ & $1 \cdot 1: 1$ & $1 \cdot 2: 1$ & $0 \cdot 7: 1$ & $0 \cdot 9: 1$ \\
\hline
\end{tabular}

*\% of total entry in parentheses. 
at diagnosis is shown in Table 3. In each case, there was no significant difference among the UKALL patients between those who survived four years and those who did not. The old series of four-year survivors, however, included a significantly higher proportion of patients without clinical enlargement of organs than either group of UKALL patients.

Table 3 Presenting clinical features

\begin{tabular}{|c|c|c|c|}
\hline \multirow{2}{*}{$\begin{array}{l}\text { Clinical enlargement } \\
\text { of: }\end{array}$} & \multirow[t]{2}{*}{ Old series } & \multicolumn{2}{|c|}{ New series } \\
\hline & & $\begin{array}{l}\text { Alive at } \\
4 \text { years }\end{array}$ & $\begin{array}{l}\text { Died before } \\
4 \text { years }\end{array}$ \\
\hline Spleen & $\begin{array}{l}43 / 83 \\
(52 \%)\end{array}$ & $\begin{array}{l}257 / 366 \\
(70 \%)\end{array}$ & $\begin{array}{l}227 / 307 \\
(74 \%)\end{array}$ \\
\hline Liver & $\begin{array}{l}40 / 81 \\
(49 \%)\end{array}$ & $\begin{array}{l}258 / 366 \\
(70 \%)\end{array}$ & $\begin{array}{l}231 / 307 \\
(75 \%)\end{array}$ \\
\hline Lymph nodes & $\begin{array}{l}40 / 82 \\
(49 \%)\end{array}$ & $\begin{array}{l}290 / 366 \\
(79 \%)\end{array}$ & $\begin{array}{l}249 / 307 \\
(81 \%)\end{array}$ \\
\hline
\end{tabular}

From Fig. 1 it can be seen that the proportions of patients with low total leucocyte and blast counts, and with relatively high platelet counts, are highest in the old series and lowest in the UKALL patients who died before four years, the new series of fouryear survivors occupying an intermediate position. The distribution of total leucocyte counts among the new series of four-year survivors, in contrast to the clinical features in Table 3 , does not differ significantly from that of the old series but is highly significantly different from that of the UKALL patients who died before four years. The distribution of blast counts among the new series of four-year survivors differs significantly from both the other groups, though more markedly from those who failed to survive for four years. In the case of the platelet counts, no significant difference is seen between the UKALL patients who did or did not survive for four years, but the old series of four-year survivors contained a significantly higher proportion with platelet counts above $100 \times 10^{9} / 1$ than either of the UKALL groups. These findings suggest that modern treatment has almost obliterated the adverse prognostic significance of clinical organ enlargement, and of a low platelet count, but has had less effect in diminishing the prognostic significance of high blast counts at diagnosis.

\section{COURSE AFTER FOUR YEARS}

Three patients in the old series were lost to follow-up six, 10 , and 12 years after diagnosis, and 47 have died; no deaths have occurred more than 10 years after diagnosis, and the remaining 33 patients have survived between 12 and 26 years. The new series is still at a relatively early stage, and several can be expected to relapse within the next few years, but life-table analysis suggests that the outlook remains much better than for the old series.

The most important determinant of prognosis from four years onwards is the occurrence of a relapse within the first four years after diagnosis; in both series, the subsequent survival of patients remaining in continuous complete remission for four years is highly significantly more favourable $(P<0.0001)$ than that of patients who had suffered one or more prior relapses (Fig. 2). Comparison of the old and new series shows two advantages for the latter in this respect: a much higher proportion of them remain in continuous remission at four years

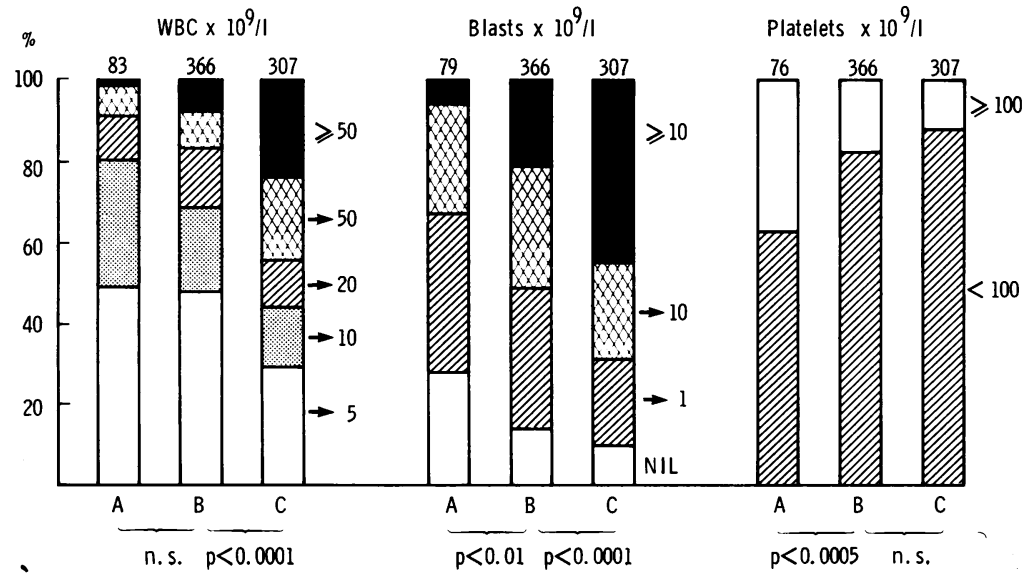

Fig. 1 Haematological findings at diagnosis. $A$, old series (diagnosed 1953-67); $B$, new series (MRC trials, diagnosed 1970-4), alive at four years; $C$, new series, died before four years. The numbers above each column indicate the totals on which each percentage distribution is based. 
[270/366 (74\%) versus 37/83 (45\%) $(\mathrm{P}<0.0001)]$, and these have a still more favourable subsequent survival $(P<0.001)$ than the corresponding group of the old series (Fig. 2). There was no significant difference between the two series in the subsequent survival of patients who had relapsed within four years.

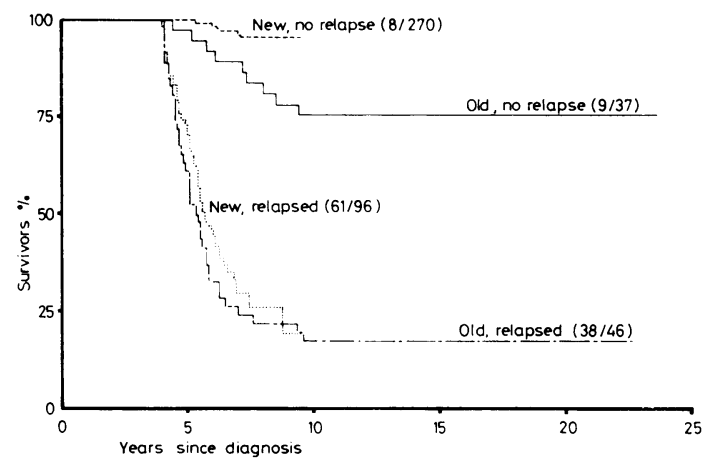

Fig. 2 Four-year survivors: life-table analysis of effect on survival of relapse within four years.

The relapse rates according to sex for those patients in the new series who were still in complete remission four years after diagnosis are shown in Figure 3. Only five of the 28 patients who have so far relapsed are girls. This sex difference is highly significant $(P<0.001)$ and remains so even if five isolated testicular relapses in boys are excluded. The greater risk of relapse for boys therefore persists beyond four but perhaps not beyond seven years (Fig. 3). The difference in subsequent survival rates, however, which are much greater for girls than for boys $(\mathrm{P}<0.001)$, is attributable chiefly to the higher proportion of boys than girls who relapsed before four years rather than afterwards (Table 2).

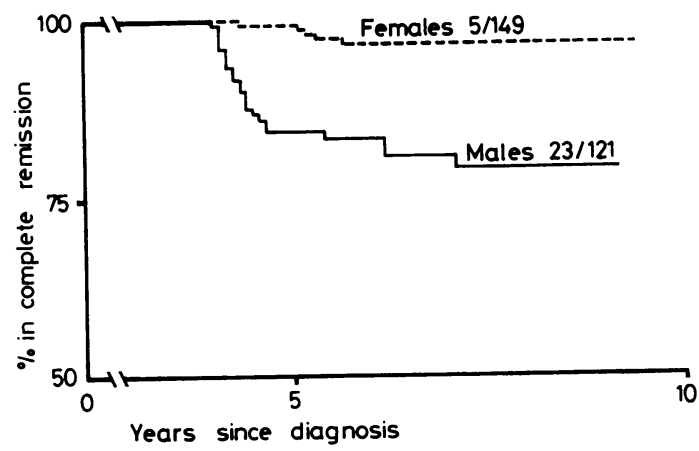

Fig. 3 Four-year continuous remissions (new series): life-table analysis of subsequent remission duration by sex.
In the old series the numbers are relatively small, but sex had no significant effect upon relapse or survival rate for those who reached four years without prior relapse: four out of 15 boys and five out of 22 girls relapsed within the next five years and all these have since died.

\section{Discussion}

Early reports of rare long survivals in acute leukaemia showed that deaths from leukaemia occurred with diminishing frequency during the fifth to 10th years after diagnosis but hardly ever thereafter. ${ }^{8}$ This observation is fully borne out by the present analysis of our original series of patients. A large cohort of patients who have been treated by combination chemotherapy with CNS prophylaxis is now entering its second decade of survival, and it remains to be determined whether the same longterm prognosis holds good for them. Meanwhile the present comparison strongly suggests that, while survival for four years despite prior relapse still carries only a slender chance of very long-term survival, four-year 'disease-free' survival now carries a still better prognosis than formerly. Moreover, of those patients surviving four years, a much higher proportion than in the previous series do so without evidence of relapse. Although first relapses have occurred in our UKALL series (mainly in boys) between four and seven years, there seems every reason to expect that the survival curve for those in first complete remission at four years will reach a plateau at about $90 \%$ by 10 years.

Why should the outlook for those achieving four-year complete remissions be better now than formerly? A possible explanation is that this group now consists mainly of patients whose leukaemic cell population has been eradicated by the treatment, whereas the old series contained a higher proportion of patients whose leukaemic cell line had not been eradicated but was merely characterised by a naturally slow rate of proliferation. Suboptimal chemotherapy would be expected to produce long remission without eradication of the disease in such cases, and the relapses soon after four years would represent the tail end of the distribution curve of natural proliferation rate of individual leukaemic cell lines. Some support for this concept is provided by the higher proportions in the old series of patients without organ enlargement at diagnosis and with low total blast-cell counts.

The benefit conveyed by female sex, which is quite independent of blast-cell count at diagnosis, is associated in both series with reduced relapse rate during the first four years and, in the new series, perhaps the first seven years after diagnosis. This 
could be explained by citing the testes as a reservoir site for leukaemic cells in boys or, since the incidence of ALL has always been greater in boys than in girls, by some more fundamental hormonal effect.

We are grateful to the Medical Research Council's Leukaemia Steering Committee and to the Working Party on Leukaemia in Childhood for permission to analyse their data in this way; and to Barbara Crossley and Carol Hermon for computing assistance.

The work was supported by the Leukaemia Research Fund.

\section{References}

1 Till MM, Hardisty RM, Pike MC. Long survivals in acute leukaemia. Lancet 1973 ;i:534-8.

2 Medical Research Council's Working Party on Leukaemia in Childhood. Treatment of acute lymphoblastic leukaemia: effect of 'prophylactic' therapy against central nervous system leukaemia. $\mathrm{Br}$ Med J 1973;ii: $381-4$.

${ }^{3}$ Medical Research Council's Working Party on Leukaemia in Childhood. Analysis of treatment in childhood leukaemia. II. Timing and the toxicity of combined 6-mercaptopurine and methotrexate maintenance therapy. Br J Haem 1976;33:179-88.

4 Medical Research Council's Working Party on Leukaemia in Childhood. Treatment of acute lymphoblastic leukaemia; effect of variation in length of treatment on duration of remission. Br Med J 1977;2:495-7.

${ }^{5}$ Medical Research Council's Working Party on Leukaemia in Childhood. Effects of varying radiation schedule, cyclophosphamide treatment, and duration of treatment in acute lymphoblastic leukaemia. $\mathrm{Br} M e d J$ 1978;2: 787-91.

- Medical Research Council's Working Party on Leukaemia in Childhood. Analysis of treatment in childhood leukaemia. V. Advantage of reduced chemotherapy during and immediately after cranial irradiation. $\mathrm{Br} J$ Cancer 1977;36:625-33.

${ }^{7}$ Peto R, Pike MC, Armitage P, et al. Design and analysis of randomised clinical trials requiring prolonged observation of each patient. II. Analysis and examples. Br J Cancer 1977;35:1-39.

${ }^{8}$ Burchenal JH. Long-term survivors in acute leukemia and Burkitt's tumor. Cancer 1968;21:595-9.

Requests for reprints to: Professor RM Hardisty, Department of Haematology, The Hospital for Sick Children, Great Ormond Street, London WC1N 3JH. 